\title{
Judicialização do Direito à Educação
}

\author{
Prof ${ }^{a}$ Dra. Ana Elisa Spaolonzi Q. Assis (PQ), Larissa R. da Silva (IC), Carolaine P. Moreira (EM), \\ Fabrício F. Ansante (EM), Victória C. Felix (EM).
}

\section{Resumo}

O presente trabalho trata de um dos objetivos específicos do projeto Judicialização do Direito à Educação, que visa consolidar o diálogo entre as ciências a partir da leitura do livro "Um Discurso Sobre As Ciências", do autor português Boaventura de Sousa Santos.

Palavras Chave: Educação, Cidadania, Diálogo Cientifico.

\section{Introdução}

O Programa Institucional de Bolsas de Iniciação Científica para o Ensino Médio (PIBICEM) tem como objetivo despertar a vocação científica nos alunos do Ensino Médio.

As atividades dos alunos vinculados ao projeto "Judicialização do Direito à Educação" foram realizadas no Laboratório de Políticas Públicas e Planejamento Educacional (LaPPlanE), da Faculdade de Educação da Universidade Estadual de Campinas (UNICAMP).

Após a leitura do livro "Um Discurso Sobre as Ciências"1, foram discutidos os paradigmas citados pelo autor.

Com o e-book "Metodologias do Trabalho Científico: Métodos e Técnicas da Pesquisa e do Trabalho Acadêmico"2 foram estudados os diversos métodos de pesquisa.

Por fim, utilizando o conteúdo estudado com o livro de Santos e pensando nos métodos de pesquisa citados no e-book, foi desenvolvida a atividade da Árvore de Problemas.

\section{Resultados e Discussão}

A primeira atividade foi feita a partir da leitura e da reflexão do livro de Santos (2010). Mapas-mentais (diagramas voltados para a gestão de informações) foram confeccionados, buscando expressar de forma sucinta as principais ideias do autor. Essa atividade exigiunos trabalho coletivo e discussões acerca do conteúdo a ser colocado no mapa-mental.

No estudo dos métodos de pesquisa, cada aluno ficou responsável por apresentar um método para os colegas, o que exigiu uma busca por informações que auxiliaria na compreensão e no desenvolvimento das atividades, buscando associar o método estudado com o nosso cotidiano escolar.

Utilizando o conhecimento adquirido com as duas leituras, foram confeccionadas Árvores de Problemas, que tinham como objetivo identificar problemas dentro da escola e buscar possíveis soluções para o problema, pensando no diálogo científico e nos métodos de pesquisa. Para cada disciplina foi proposta uma atividade que contribuiria para a solução do problema.

\section{Conclusões}

Todo o conteúdo estudado nos possibilitou adquirir uma visão mais ampla a respeito da pesquisa científica dentro da universidade, além de mostrar-nos as diversas opiniões em relação a distinção entre as ciências.

Dentro do ambiente escolar, o projeto nos possibilitou adquirir melhor entendimento nas disciplinas de Filosofia e Sociologia, na forma de pensar, refletir e estudar a sociedade como um todo.

As discussões e reflexões realizadas durante os encontros possibilitaram-nos desenvolver nosso pensamento crítico, formar nossas opiniões a partir de argumentos sólidos que contribuirão para nossa atuação no mundo enquanto cidadãos.

\section{Agradecimentos}

À Pró-Reitoria de Pesquisa (PRP) e ao Conselho Nacional de Desenvolvimento Científico e Tecnológico (CNPq) pelo apoio e auxílio;

Aos colegas do Laboratório de Políticas Públicas e Planejamento Educacional (LaPPlanE);

À nossa orientadora, Prof ${ }^{-}$. Dra. Ana Elisa Spaolonzi Queiroz Assis.

\footnotetext{
'SANTOS, Boaventura de Sousa. Um Discurso sobre as Ciências. São Paulo, SP: Cortez, 2010.

2 PRODANOV, Cleber Cristiano; FREITAS, Ernani Cesar de. Metodologia do Trabalho Científico: Métodos e Técnicas da Pesquisa e do Trabalho Acadêmico. $2^{a}$ Ed. Novo Hamburgo, RS: Feevale, 2013.
} 